\title{
Seasonal Distribution and Migration of the Common Mackerel in the Southwestern Japan Sea and the East China Sea*1
}

\author{
Daniel Limbong, ${ }^{* 2}$ Kohachi Hayashi, ${ }^{* 3}$ and Kunio Shirakihara*2 \\ (Received July 2, 1990)
}

\begin{abstract}
Seasonal changes in the distribution of the common mackerel were examined using catch statistics of the Japanese large purse seine fishery (years of 1974-1988). Concentrations with high CPUE appeared in the southwestern Japan Sea in November-December. They expanded to the waters near Cheju island in January-April, but only remained in the southwestern Japan Sea near May. Concentrations in this sea almost disappeared in summer. The Tsushima current stock was estimated to move southwards from autumn to winter and move northwards from the wintering area after spring. Some yearly variations of the time to start migration were observed. The density index of the wintering group was proposed to describe the yearly fluctuation of this stock. It was estimated that the size of this stock has decreased since 1977, and its distribution area has also reduced. Concentrations also appeared in the middle and southern East China Sea, which was considered to belong to the East China Sea stock. Due to the lack of data, a migration pattern of this stock was presented as a preliminary result.
\end{abstract}

The common mackerel, Scomber japonicus, has been commercially important in the southwestern Japan Sea and the East China Sea. Its catch occupied more than $50 \%$ of the total catches of pelagic fish species exploited by the Japanese large type purse seine fishery from 1973 to 1976 in the latter sea. ${ }^{1)}$ Its catch, however, has decreased gra dually since the middle of 1970 s, which gives more attention to the population dynamics studies of the fish.

This study aims to determine seasonal changes in the distribution and estimate a migration pattern using the latest catch statistics of the Japanese large type purse seine fishery which is the main fishery for the fish. Several studies on these matters were carried out by means of tagging experiments ${ }^{2,3)}$ and analysis of catch statistics. $\left.{ }^{4}, 5\right)$ But considering that many pelagic fish populations show dynamic changes in the distribution with population fluctuation, ${ }^{\text {s) }}$ updated information would be worth-while. Recently, a preliminary study has been done by Hayashi and Hama-

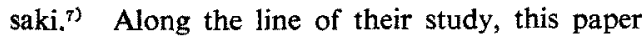
attempts to make more detailed analyses using well arranged data. Furthermore this focus on determining a definition of a population as a unit for the population dynamics studies.

\section{Methods}

Catch statistics of the Japanese large type purse seine fishery in the southwestern Japan Sea and the East China Sea are available through the Japan Fisheries Agency. Raw data include catch in weight and fishing effort in numbers of hauls by day and by fishing area $\left(10^{\prime} \times 10^{\prime}\right.$ rectangle). These data for the period of 1974-1988 were compiled by area of $30^{\prime} \times 30^{\prime}$ rectangle and by time interval of about ten days (each month is divided into 3 intervals). Then the corresponding catch per unit effort (CPUE) was computed. If no fishing took place within a rectangle, its CPUE value was considered to be zero. These CPUE grid data were used to construct CPUE contour maps for every ten days with a computer program written by Shiono et al. ${ }^{8)}$ A perspective of the seasonal changes in the distribution and movement was given from observation of timespace shift in high concentrations on the maps.

*1 A part of this study was presented at the Annual Meeting of the Japanese Society of Scientific Fisheries in October 1989, Miyazaki.

*2 Graduate School of Marine Science and Engineering, Nagasaki University, Nagasaki 852, Japan (D. Limbong, 白木原国雄：長踦大学海洋生程科学研究科).

*3 Nansei National Fisheries Research Institute, Ohno, Hiroshima 739-04, Japan（林 小八：南西海区水 産研究所). 


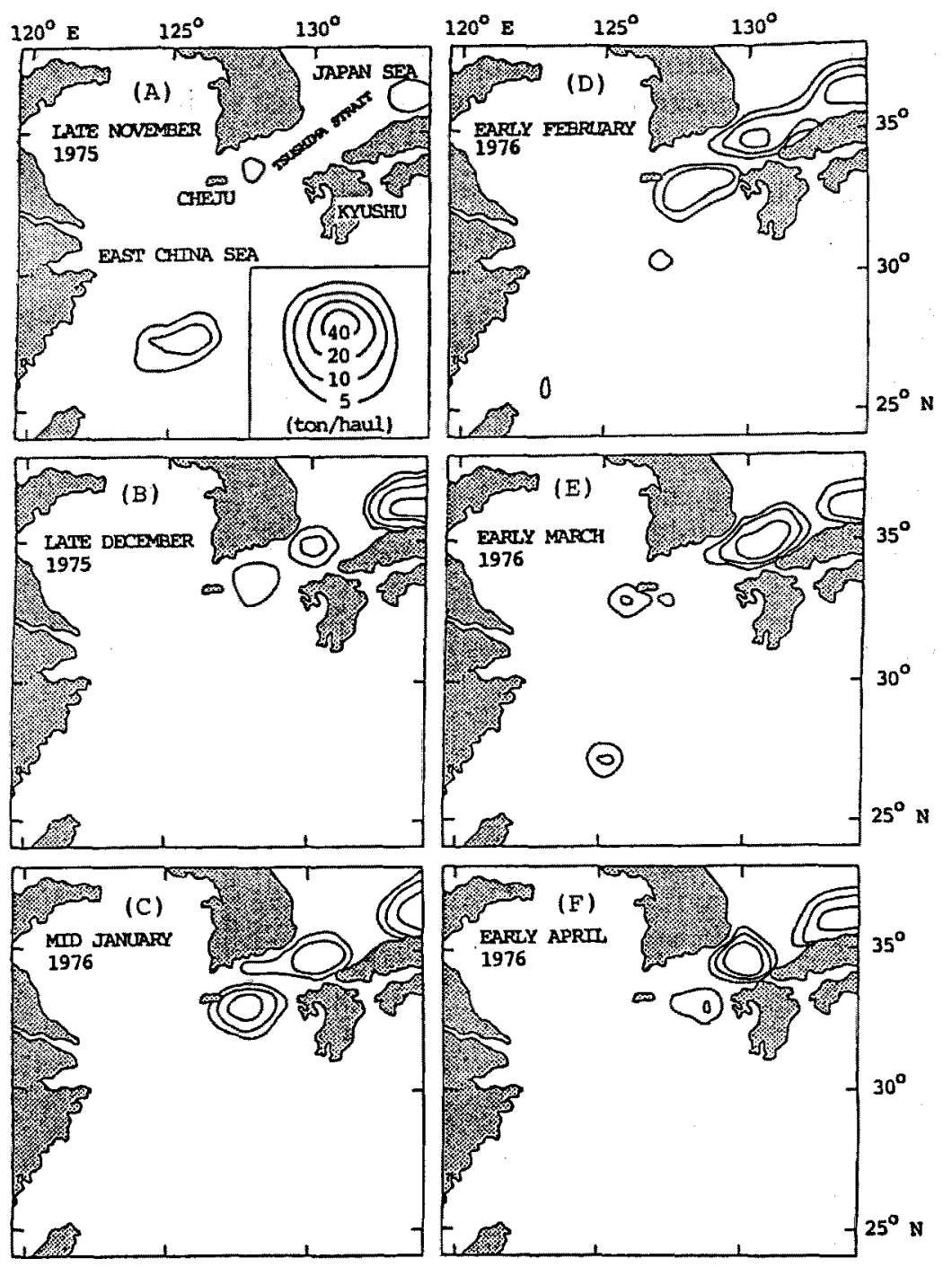

Fig. 1. Catch per unit effort (CPUE) contour maps for the common mackerel in 1975-1976.

\section{Results and Discussion}

\section{Seasonal Changes in the Distribution}

As a typical example, 12 contour maps from November in 1975 to October in 1976 are shown in Fig. 1. Concentrations of CPUE were mainly found from waters between the northwestern Kyushu and Cheju island to the southwestern Japan Sea through a year. Therefore, our attention will be initially restricted to this area.

In late November, two concentrations with low CPUE ( $<10$ ton/haul) were observed (Fig. 1A). In late December, CPUE of a concentration in the east end became more than 20 ton/haul (B). In January and February, areas with high CPUE expanded (C and D), In March and April, CPUE near waters between Kyushu and Cheju became low but that in the southwestern Japan Sea remained high ( $E$ and $F$ ). In May and June, only one concentration with high CPUE was observed in the east end ( $G$ and $H$ ). In the summer season from July to September, concentrations almost disappeared (I-K) except a concentration in adjacent waters of Cheju (J). In October, a concentration with low CPUE was observed near Cheju island (L). 


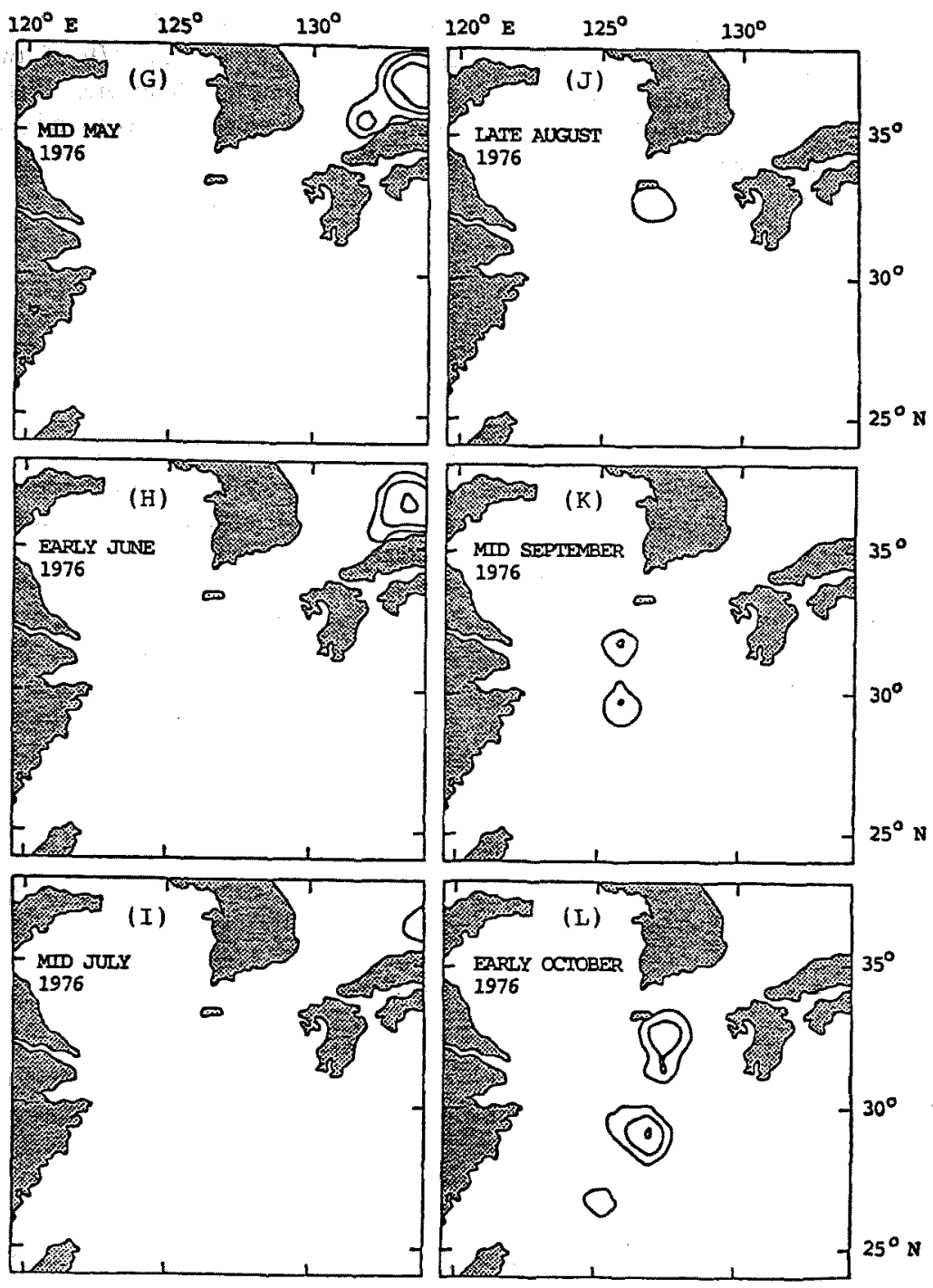

Fig. 1. Continued.

Seasonal shifts in concentrations in the East China Sea were attempted to be examined, but lack of data made it difficult to clarify a clear trend. In November and March, a concentration was observed in the southern waters respectively ( $A$ and E). From August to October, concentrations seemed to shift southwards (J-L).

Catch and effort statistics only provide information on densities of the common mackerel in fishing areas, but if the fish is a target species for the fishery, the fishing areas will reflect the distribution areas. To check this, the effectiveness of fishing effor ${ }^{\theta)}(\varepsilon)$ was calculated in the main fishing area (Fig. 2):

$$
\varepsilon=\tilde{X} / X=\left(A C / \sum_{i} A_{i} \mathrm{CPUE}_{i}\right) / X
$$

where $X$ and $\tilde{X}$ are fishing effort and effective fishing effort, respectively. Symbols of $A_{i}$ and $A$ are the $i$-th $30^{\prime} \times 30^{\prime}$ rectangle and total area, respectively, and $C$ is catch in the total area. The obtained values of $\varepsilon$ were larger than unity except one case in March 1988 (Table 1), which means that fishing were carried out in the higher density areas. This suggests that the fish was a target species and that seasonal shifts in concentrations in fishing areas mentioned above could reflect those in the distri- 


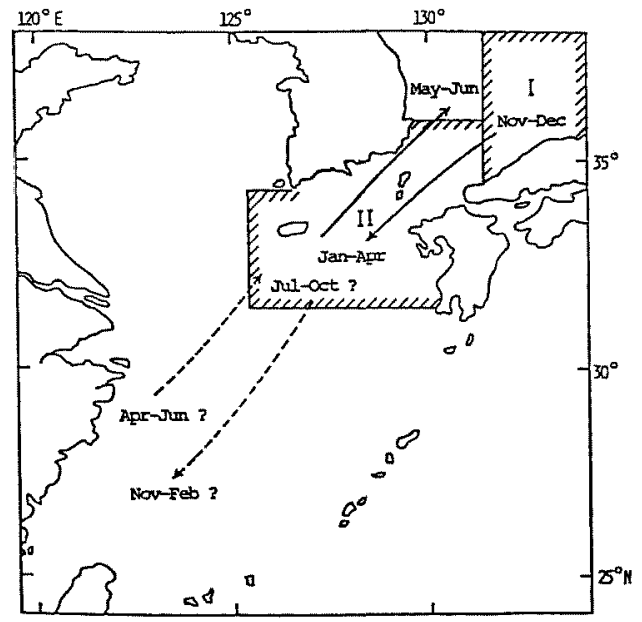

Fig. 2. A definition of the main fishing area (subdivision I+II) and the migration routes estimated from CPUE contour maps in Fig. 1. Interrupted arrows show the routes estimated preliminarily.

Table 1. The effectiveness of fishing effort for the common mackerel in the area defined in Fig. 2

\begin{tabular}{lcccc}
\hline & Nov. & Jan. & Mar. & May \\
\hline $1975-1976$ & 2.95 & 2.11 & 3.88 & 1.94 \\
$1979-1980$ & 2.27 & 1.79 & 2.02 & 1.83 \\
$1983-1984$ & 1.99 & 1.49 & 2.56 & 2.30 \\
$1987-1988$ & 4.97 & 2.65 & 0.98 & 3.70 \\
\hline
\end{tabular}

bution.

\section{Yearly Variations of Seasonal Changes}

Yearly variations of seasonal changes in the distribution were examined by comparing seasonal changes of density indices ${ }^{\theta)}(\tilde{D})$ of two subdivisions of the main fishing area (Fig. 2). The index of each subdivision was given by the following formula:

$$
\widetilde{D}=\sum_{i} A_{i} \mathrm{CPUE}_{i} / A
$$

Seasonal changes of $\widetilde{D}$ for a main fishing period from November to May are shown in Fig. 3.

As a general pattern in the subdivision $\mathbf{I}$, three peaks with high densities were observed near November, January and April. Let's compare a seasonal trend in 1975-1976 (Fig. 3A) with contour maps (Fig. 1). The third peak near April corresponds to the high concentration in Fig. 1F. As for II, one peak appeared near December -January. Seasonal trends in both subdivisions should be interrelated if the fish move regularly with a fixed route every year. Certainly, a decrease in density after the period of the first peak in I was accompanied by an increase in II except for 1981-82 and 1985-86, where the first peak in I seemed unclear. Furthermore, an increase before the period of the third peak in I almost corresponded with a decrease in $\mathbf{I I}$. This implies that seasonal changes in densities bave a yearly unchanged pattern though the periods of the peaks. have some yearly variations, and therefore that seasonal changes in the distribution also have such a pattern.

\section{Migration}

A migration pattern as shown in Fig. 2 was estimated from the seasonal changes in distributions. Contour maps (Fig. 1) suggest existence

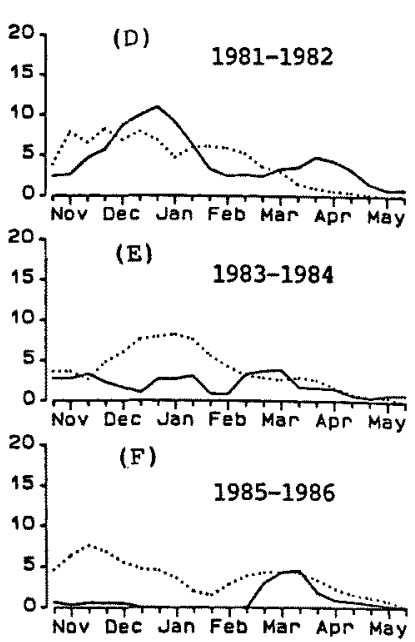

Fig. 3. Seasonal fluctuation of density indices in subdivision $I$ and $I$ for the main fishing season. 


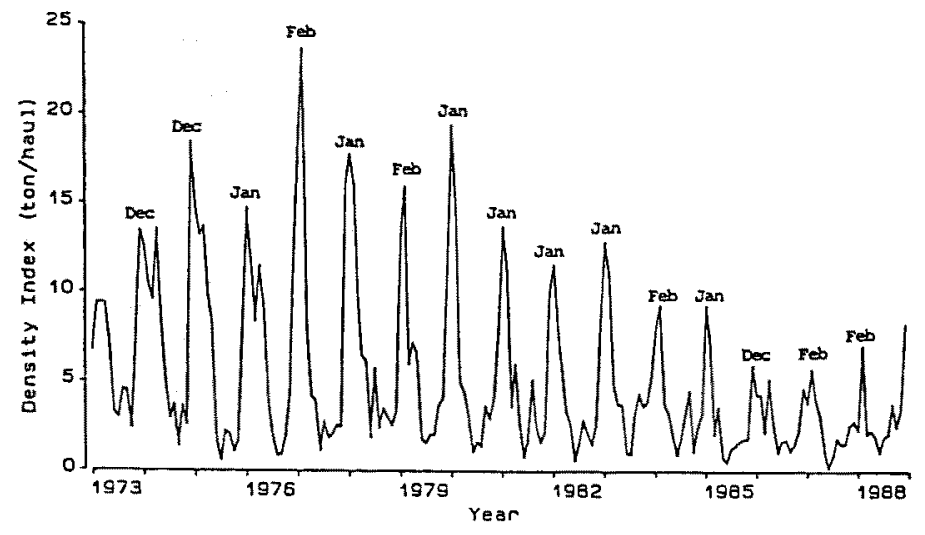

Fig. 4. Monthly and yearly fuctuation of density index in the area defined in Fig. 2 (subdivision I+II) with month at peak.

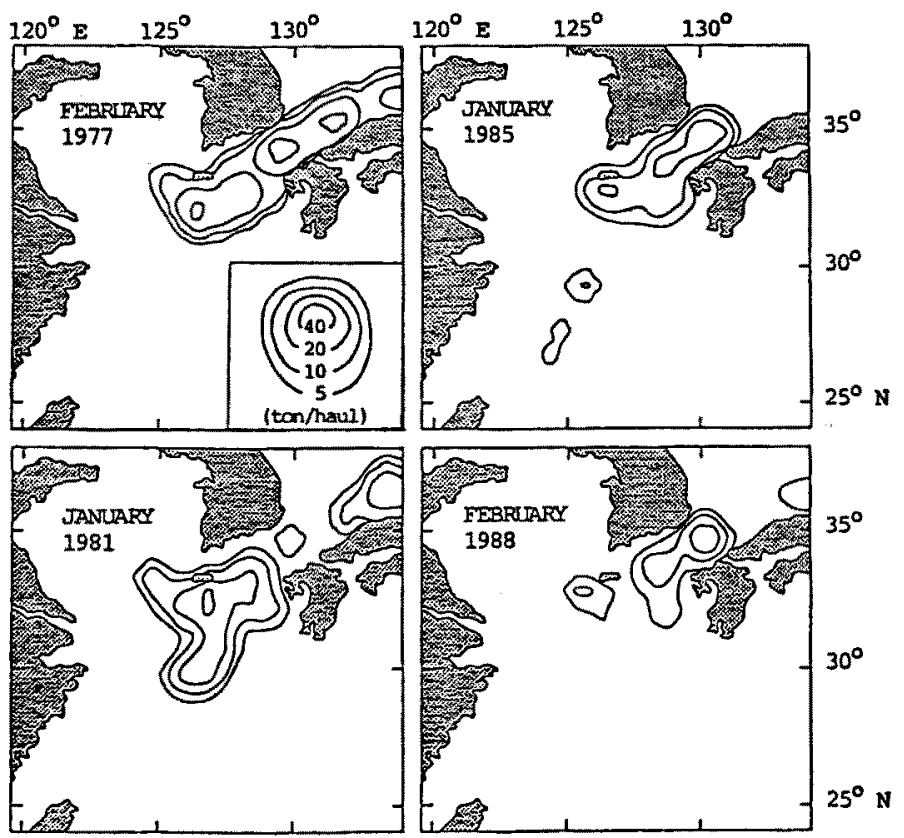

Fig. 5. Contour maps to examine the relation between distribution area and fluctuation of the Tsushima current stock. The stock size is estimated to decrease after 1977.

of two different groups; one distributed in the waters off Kyushu and the southwestern Japan Sea and the other in the central and southern waters of the East China Sea. According to the studies on stock identification, ${ }^{4}$ the former and the latter belong to Tsushima current stock and East China stock, respectively. As for the former, the fish distributed in the southwestern Japan Sea near November and December tend to move southwards. The area defined in Fig. 2 is considered to be the main wintering area of this stock. In spring, the fish tend to move northwards. Such a wintering migration pattern coincides with the one estimated by tagging experiments. $^{32}$

Migration pattern of the fish of the East China Sea stock is unclear because lack of data. However, southward migration from adjacent 
waters of Cheju (Fig. 1J-L) agrees with the pattern evaluated by Hayashi and Hamasaki ${ }^{\text {r) }}$ and by Zhu et al. ${ }^{10)}$

\section{Definition of a Population as a Unit of Dynamics Studies}

The estimated migration pattern predicts that at least a portion of the fish gathering near Tsushima strait, will surely move northwards beyond the current study area after spring. Therefore, such fish should be considered to constitute an open population in the current study area. The estimated pattern, however, suggests the following method to examine the yearly fluctuation of the Tsushima current stock. First, a population is assumed which consists of the fish in the area defined in Fig. 2 in winter. Then the density index $(\widetilde{D})$ of the population may be safely used as an index of the Tsushima current stock size. Fig. 4 shows the monthly and yearly change of $\tilde{D}$ in this area. Certainly, peaks appear in every winter. Yearly change of $\tilde{D}$ in winter may indicate the stock fluctuation. One problem in this method is that $\widetilde{D}$ can not serve the stock index if contribution of other stock(s) in the wintering area is significant in the area defined above. In the present situation where stock identification is not fully confirmed, future studies are needed to overcome this problem.

\section{Distribution Area and Stock Fluctuation}

The Tsushima current stock is estimated to decrease in size after 1977 (Fig. 4). Fig. 5 shows contour maps in the months when density index was the highest of winter. In 1977 , distribution area with CPUE more than 5 ton/haul almost covered waters off Kyushu and the southern Japan Sea. In 1981, CPUE near Tsushima strait became low. In 1985 and 1988, both the distribution area and CPUE reduced, especially in the southwestern Japan Sea. The common mackerel shows a flexible reduction in distribution with a reduction of the stock size.

\section{Acknowledgments}

The authors are indebted to Professor K. Takeshita, Shimonoseki University of Fisheries (former director of Seikai National Fisheries Research Institute, Shimonoseki Branch) who provided the catch statistics used in this study. We also thank to Dr. K. Teshima and I. Hara, Seikai National Fisheries Research Institute for their kind advices on handling the statistics. The authors are indebted to Dr. Y. Natsukari, Nagasaki University, Faculty of Fisheries for his encouragement and help in preparing the manuscript.

\section{References}

1) K. Takeshita and K. Hayashi: in "Proceeding of symposium on development of marine resources and international cooperation in the Yellow Sea and the East China Sea" (ed. by You-Bong GO), Marine Research Institute Cheju National University, Cheju, Korea, 1988, pp. 113-129.

2) S. Machinaka: Ann. Rept. Jap. Sea Reg. Fish. Res. Lab., 6, 105-126 (1960).

3) H. Ohkawa: Bull. Seikai Reg. Fish. Res. Lab., 47, 15-50 (1975).

4) A. Ouchi and S. Hamasaki: Bull. Seikai Reg. Fish. Res. Lab., 53, 125-152 (1979).

5) K. Iizuka and S. Hamasaki: Bull. Seikai Reg. Fish. Res, Lab., 63, 15-48 (1986).

6) T. Nakahara and Y. Ogawa: Bull. Jap. Soc. Fish. Oceanography, 34, 21-31 (1979).

7) K. Hayashi and S. Hamasaki: Bull. Jap. Soc. Fish. Oceanography, 51, 249-254 (1987).

8) K. Shiono, S. Matsumoto, and K. Wadatsumi: Basic ni yoru contour map (Basic programs for contour map) II, Kyoritsu Shuppan, Tokyo, 1988, pp. 121-129.

9) S. Tanaka: Suisan Shigengaku Soron (Fish population Dynamics), Koseisha-Koseikaku, Tokyo, 1985, pp. 193-198.

10) D. Zhu, L. Wang, G. Zhang, and F. Ly: Marine Fish. Res., 4, 17-31 (1982). 